\title{
Using combined recombinant protein in the diagnosis of bovine brucellosis
}

\author{
AITBAY BULASHEV, TADEUSZ JAKUBOWSKI*, KANATBEK MUKANTAYEV**, \\ KANAT TURSUNOV, VLADIMIR KIYAN, AIBEK ZHUMALIN
}

\begin{abstract}
S. Seifullin Kazakh Agro-Technical University, Zhenis avenue 62, 010011, Astana, Kazakhstan
*Warsaw University of Life Sciences, Nowoursynowska street 159, 02-776, Warsaw, Poland

**National Center for Biotechnology of the Republic of Kazakhstan, Korgalzhyn highway 13/5, 010000, Astana, Kazakhstan
\end{abstract}

Bulashev A., Jakubowski T., Mukantayev K., Tursunov K., Kiyan V., Zhumalin A.

Using combined recombinant protein in the diagnosis of bovine brucellosis

\section{Summary}

The aim of this research was to obtain a combined recombinant protein consisting of immunodominant regions of Brucella outer membrane proteins (Omps) with the molecular weights of $25 \mathrm{kDa}(\mathrm{Omp} 25)$ and 31 kDa (Omp31). The search for candidate proteins was carried out using NCBI PubMed and NCBI GenBank databases. The two most immunodominant regions of Omps were selected. The first region was in a position from 48 to 83 amino acids of Omp31, while the second one was in the position from 180 to 224 amino acids of Omp25. This combined sequence was designated as OmpBm-Ba. The pET32 vector was used for cloning and the expression of the combined recombinant protein in E. coli BL21(DE3). The antigenicity of recombinant OmpBm-Ba (rOmpBm-Ba) as compared with rOmp25 and rOmp31 has been tested on the sera of 109 cattle with positive results to brucellosis according to classical serological tests. The rOmpBm-Ba had a higher antigenicity than the single ones, since it confirmed the presence of Brucella-antibody in all serum samples with positive results of i-ELISA/rOmp25 and/or i-ELISA/rOmp31, as well as additionally revealing $7.3 \%$ and $31.2 \%$ seropositive animals, respectively. A comparative study of the diagnostic value of i-ELISA/rOmpBm-Ba and conventional tests on blood sera of 24 cattle subjected to a bacteriological examination at slaughter showed a higher reliability of enzyme immunoassay. Further research is necessary to get a more objective evaluation of the diagnostic accuracy of Brucella rOmpBm-Ba by challenging laboratory animals.

Keywords: brucellosis, Brucella outer membrane proteins, antigenicity, serological diagnosis, ELISA

Brucellosis is endemic in Asia, Sub-Saharan Africa, some countries of Latin America, the Middle East and the Mediterranean and South Eastern Europeean Region (30). The disease causes not only great economic losses in animal husbandry, but also poses a serious threat to public health $(2,15)$. A complicated epizootic and epidemiological situation for brucellosis persists in the Republic of Kazakhstan where the disease remains endemic $(21,33)$. The efficacy of brucellosis control and eradication programs primarily depends on the timely detection of infected animals by serological tests. The conventional serological tests for diagnosing bovine brucellosis in Kazakhstan are the agglutination test (AT), complement fixation test (CFT) and rose bengal test (RBT). These tests which are based on the use of Brucella cells smooth lipopolysaccharides (S-LPS) as an antigen do not always give reliable results because of cross-reactivity with other Gram-negative bacteria $(3,14,37)$. Therefore, there has been an ongoing search for non-LPS candidates, namely protein antigens, for the diagnosis of brucellosis $(12,13,22)$.

Outer membrane proteins (Omps) of Brucella spp. were originally identified on the basis of their molecular weight (mol.wt.) (29). Group 1 was identified as minor (94 or $88 \mathrm{kDa})$. Major Brucella Omps have been classified in group 2 (36 to $38 \mathrm{kDa}$ ) and group 3 (Omp25 and Omp31) (11). Moreover, Omp28 was identified as another member of group 3 (26). The latter has been approved as useful for the differentiation of infected sheep from vaccinated ones (16). Several recombinant Omps (rOmps), including those with lower mol.wt., were obtained and tested in ELISA a for serological diagnosis of animal brucellosis like rOmp10, rOmp19 and rOmp28 (34), rOmp16 (20), rOmp25 (10), rOmp28 $(9,25,27)$ and rOmp31 (18). The main obstacle for introducing these recombinant proteins into diagnostic practice is their lack of sensi- 
tivity for detecting antibodies against the single rOmp (24). For example, rOmp31 showed insufficient antigenicity to antibodies of patients and animals infected with brucellosis (8). According to the authors, indirect enzyme-linked immunosorbent assay (i-ELISA) using rOmp31 made it possible to diagnose brucellosis in only $48 \%$ of people, and identify an infection only in $61 \%$ and $87 \%$ of sheep and dogs, respectively. The low diagnostic value of a single rOmp in serological diagnosis for bovine brucellosis was also established in our previous studies (6). For instance, soluble saltextractable protein antigens (CSP) from Brucella spp. were significantly superior to the rOmp 28 by its antigenicity in i-ELISA. In addition, antibodies against this protein were not detected in the serum of $8.2 \%$ of cows reacting positively to brucellosis by the results of conventional serological tests. In this regard, it is of great practical interest to use combination of more than one recombinant protein in the development of ELISA in order to increase its sensitivity. Ahmed I.M. et al. (1) found that the combined use of rOmp25, rOmp28 and rOmp31 significantly increases the specificity of ELISA in the detection of anti-Brucella antibodies. The results have showed that ELISA based on the cocktail of rOmps has the ability to detect Brucellaantibodies in mice due to infection rather than vaccinal or cross-reacting ones. Thus, the use of a multiprotein diagnostic reagent in serological tests may open up new prospects for the improvement of serological diagnosis of brucellosis.

The aim of this research was to obtain a combined recombinant protein consisting of immunodominant regions of Brucella Omp25 and Omp31, and determining its antigenic properties on blood sera from cattle positively reacting to brucellosis.

\section{Material and methods}

Recombinant proteins and soluble salt-extractable protein (CSP) of B. abortus. Brucella rOmp25 and rOmp31 used in this study were obtained in our earlier research (5). The extraction of CSP from Brucella cells was carried out according to the method of Tabatabai and Deyoe (35).

Serum samples. One hundred and nine sera collected from cows positive to brucellosis according to AT and/or CFT and 24 serum samples of cows which were subjected to bacteriological examination were kindly provided by the Republican Veterinary Laboratory and National Veterinary Reference Center, the Ministry of Agriculture of the Republic of Kazakhstan. For calculating a cutoff value of i-ELISA blood sera were obtained from 19 heifers of the „Rodina” farm, Akmola region, Kazakhstan, which was free of brucellosis for long periods of time.

Bacterial strains, plasmids, and growth conditions. E. coli $\mathrm{DH} 5 \alpha$ and E. coli BL21(DE3) were used for the transformation of recombinant plasmids. The cell cultures were grown on LB broth and LB agar media (Thermo Fisher Scientific, Waltham, USA), supplemented with ampicillin at the concentration of $100 \mu \mathrm{g} / \mathrm{ml}$ (Sintez, Kurgan, Russia).
The pET32 vector was used for cloning and the expression of the recombinant protein in E. coli.

Construction of the combined Brucella recombinant protein. The search for candidate proteins was carried out using the NCBI PubMed (http://www.ncbi.nlm.nih.gov/ pubmed) and NCBI GenBank databases (http://www.ncbi. nlm.nih.gov/genbank). Bioinformatics research and planning genetic engineering studies were carried out using the Vector NTI 11.5 software package (Invitrogen, USA). Based on the studies of Vizcaino N. et al. (38-40), the two most immunodominant regions of Brucella Omps were selected. The first region is in a position from 48 to 83 amino acids of Omp31, and the second one is in the position from 180 to 224 amino acids of Omp25. These sequences were designated as OmpBm-Ba. To create alignments, the AlignX program from the Vector NTI 11.5 package was used (Invitrogen, USA). Reverse translation was performed using BackTranslation tool, controlling the possibility of the appearance of hairpins in the 5'-end region of the gene. Nucleotide sequence encoding OmpBm-Ba was synthesized by Invitrogen (Life Technologies, Carlsbad, USA) in lyophilized form at a concentration of $5 \mu \mathrm{g}$ DNA.

Cloning, expression and purification of the recombinant protein. The synthesized DNA sequence of the combined Brucella OmpBm-Ba was obtained in the pMK-RQ vector and then digested by the restriction enzymes NcoI and XhoI (Thermo Fisher Scientific, Waltham, USA) with $10^{\mathrm{x}}$ Tango buffer (Thermo Fisher Scientific, Waltham, USA) and ligated into an expression vector using T4 DNA-ligase (Thermo Fisher Scientific, Waltham, USA). The ligated product was transformed into E. coli $\mathrm{DH} 5$ and cultivated overnight at $37^{\circ} \mathrm{C}$ with shaking. The plasmids were purified using QIAprep Spin Miniprep Kit (Qiagen, Hilden, Germany) according to the manufacturer's instructions. The sequence of the cloned product was confirmed by Sanger et al. (31) using the BigDye sets and automatic DNA analyzer ABI Prism 3100 (Applied Biosystems, USA). Next, E. coli $\mathrm{BL} 21(\mathrm{DE} 3)$ cells were transformed by the obtained construction of OmpBm-Ba/pET32 and incubated at $37^{\circ} \mathrm{C}$ overnight on LB agar plates with ampicillin. The single colony was used to inoculate in $5 \mathrm{ml}$ LB with an antibiotic and incubated overnight at $37^{\circ} \mathrm{C}$ with shaking. Four hundred $\mathrm{ml}$ of LB broth were inoculated with $5 \mathrm{ml}$ over night culture and Isopropyl $\beta$-D-1-thiogalactopyranoside (IPTG) (Sigma-Aldrich, St. Louis, USA) was added to a final concentration of $1 \mathrm{mM}$ to induce the expression of the recombinant protein. The culture was incubated for $16 \mathrm{~h}$ at room temperature (RT) with shaking and then bacterial cells were harvested by centrifugation at $5000 \times \mathrm{g}$ for $10 \mathrm{~min}$ at $4^{\circ} \mathrm{C}$. After that cells were resuspended in a lysis buffer $(20 \mathrm{mM}$ Tris $\mathrm{pH} 7,5 ; 1 \mathrm{mM}$ EDTA; $100 \mathrm{mM} \mathrm{NaCl}$ ) at the amount of $10 \mathrm{ml}$ per $1 \mathrm{~g}$ wet weight cells, followed by the addition of $1 \mu 1$ of phenylmethanesulfonyl fluoride (Thermo Fisher Scientific, Waltham, USA) with a final concentration $0.2 \mathrm{mM}$. The bacterial cell suspension was then sonicated using ultrasonic homogenizer OMNI-Ruptor 4000 (Kennesaw, USA) in an ice-water bath. The recombinant protein (rOmpBmBa) was purified using His Trap Columns (GE Healthcare Life Sciences, Cardiff, UK) based on metal affinity chromato- 
graphy according to the manufacturer's instructions. The concentration of the protein was measured by Bradford (4).

Western blot. The presence of rOmpBm-Ba was confirmed by western blot assay using anti-His Tag monoclonal antibody $(\mathrm{mAb})$ conjugated to horseradish peroxidase (HRP) (Thermo Fisher Scientific, Waltham, USA). Briefly, the combined recombinant protein was separated by SDSpolyacrylamide gel electrophoresis (SDS-PAGE) (23) and transformed to nitrocellulose membrane $(0.45 \mu \mathrm{m})$ (GE Healthcare Life Sciences, Cardiff, UK) as described by Towbin et al. (36). The membrane was blocked in $1 \%$ bovine serum albumin (BSA) (Abcam, Cambridge, USA) for $1 \mathrm{~h}$ at RT, and washed three times in phosphate buffered saline with Tween-20 (PBS-T). Anti-His Tag mAb were added in a $1: 4000$ dilution and incubated for $1 \mathrm{~h}$ at RT with shaking. After washing the membrane with PBS-T, 4-chloro-1-naphthol substrate (Sigma-Aldrich, St. Louis, USA) was added and incubated until color developed. Next, the membrane was washed in deionized water to stop the reaction and analyzed.

Determination of antigenicity of the $\mathrm{rOmpBm}-\mathrm{Ba}$ by ELISA. The polystyrene plate wells were coated with rOmpBm-Ba $(5.0 \mu \mathrm{g} / \mathrm{ml})$ in bicarbonate buffer $(0.1 \mathrm{M}$, $\mathrm{pH}$ 9.6). The plate was incubated at $4^{\circ} \mathrm{C}$ for $18 \mathrm{~h}$ and then the wells were washed six times with PBS-T. The active centers of the wells were neutralized with $1 \%$ BSA ( $1 \mathrm{~h}$ at $37^{\circ} \mathrm{C}$ ), and dilutions of test serum as well as the control (positive and negative) sera in PBS-T were prepared starting with $1: 100$, and incubated $1 \mathrm{~h}$ at $37^{\circ} \mathrm{C}$. After the washing procedure, HRP-labeled anti-bovine IgG (Sigma-Aldrich, St. Louis, USA; dilution 1 : 10,000) was added into the wells. The plate was incubated at $37^{\circ} \mathrm{C}$ for $1 \mathrm{~h}$., washed six times, and the substrate O-phenylenediamine (SigmaAldrich, St. Louis, USA) was added. The absorbance was measured at $492 \mathrm{~nm}$ using a plate reader (Bio-Rad 680, USA). A cutoff value to distinguish between positive and negative results of $\mathrm{i}$-ELISA was calculated using the mean OD of B. abortus-negative sera (17). Statistical analysis of the results of serological tests was carried out according to the method described by Sayduldin (32).

\section{Results and discussion}

The sequence of the DNA fragment of $570 \mathrm{bp}$ encoding Brucella rOmpBm-Ba, which consists of the immunodominant regions of the Omp25 and Omp31 was as follows (Fig. 1).

The single line underlines the gene encoding the linear immunogenic epitope of Omp25, the double line underlines the gene encoding the antigenic epitope of Omp31, the dashed line is the hinge separating the construction from the hexahistidine tag gene. The sequence also contains restriction sites for cloning BamHI, NcoI, XhoI, HindIII (capital letters), and 6His-Tag (italicized). The calculated protein-coding sequences are codon-optimized for the expression of the target proteins in E. coli.

The results of electrophoresis of the synthesized DNA encoding the combined recombinant protein on $1 \%$ agarose gel are shown in Fig. 2.
CCACGGATCCCCATGG cggcggatgtggtggtgagcgaaccgagcgcgccgaccgcggcgccggtggatacctttagctggaccggcggctatattggcattaacgcgggctatgcgggcggcaaatttaacatccgtttagcagctttgataaagaagataacgaacaggtgagcggcagcctggatgtgaccgcgggcggctttgtgggcggcgtgcaggcgggctataactggcagctggaaaccaaagtggaatggtttggcaccgtgcgcgcgcgcctgggctataccgcgaccgaacgcctgatggtgtatggcaccggcggcctggcgtatggcaaagtgaaaaaaaccaaagcgggctggaccctgggcgcgggcgcggaatatgcgattaacaacaactggaccctgaaaagcgaatatctgtataccgatctgggcaaacgcaacctggtggatgtggataacagctttctggaaagcaaagtgaactttcataccgtgcgcgtgggcctgaactataaatttggcggcagccaccatcatcatcatcattaaCTCGAGAAGCTTAG.

Fig. 1. The sequence of the DNA fragment of OmpBm-Ba

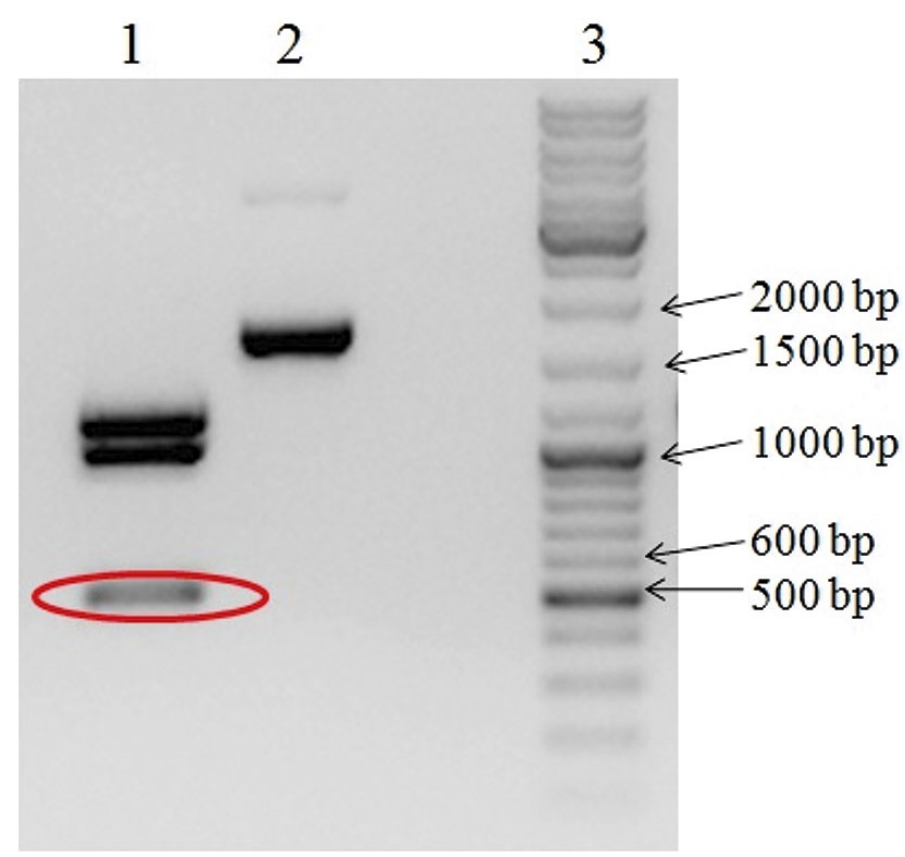

Fig. 2. Restriction fragments of OmpBm-Ba and pMK-RQ vector

Explanations: 1 - DNA fragment of OmpBm-Ba; 2 - vector pMK-RQ/OmpBm-Ba before restriction; 3 - DNA molecular weight marker

The results showed the presence of a DNA band with expected sizes of approximately $570 \mathrm{bp}$. The resulting DNA fragment was purified from the gel using a set Quick Gel Extraction Kit, ligated to the expression vectors and transformed into the E. coli BL21 (DE3) cells. The transformed $E$. coli cells were grown on LB broth and the expression of rOmpBm-Ba was induced by the addition of $1 \mathrm{mM}$ of IPTG.

SDS-PAGE data after the fractionation of cell lysates showed that the target protein is within the inclusion bodies (pellet of cell lysate) of the cells. The maximum amount recombinant protein was obtained after the treatment of the pellets with a denaturing buffer containing $8 \mathrm{M}$ Urea (data not shown).

Fig. 3 shows the results of SDS-PAGE electrophoresis of the supernatant from the inclusion bodies 


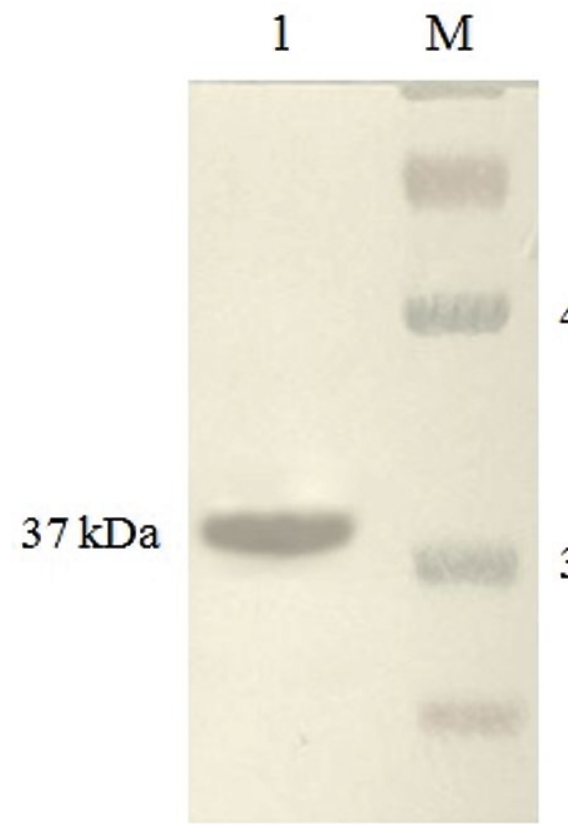

Fig. 4. Western blot analysis of the combined recombinant protein using His Tag MAb

Explanations: 1 - rOmpBm-Ba; $\mathrm{M}$ - protein molecular weight marker

purified by metal affinity chromatography using His Trap columns (Fig. 3).

As seen from Fig. 3, the combined recombinant protein has an apparent mol.wt. of $37.0 \mathrm{kDa}$. The presence of rOmpBm-Ba in the lysate of the transformed cells after expression was also confirmed by a western blot assay using HRP-conjugated anti-His Tag mAb (Fig. 4).

The results of immunoblotting show that the MAb recognizes His Tag label of the combined recombinant protein with the same mol.wt.

The antigenicity of rOmpBm-Ba was tested on the serum samples of 109 cows positively reacting to brucellosis by AT and/or CFT. To determine the cutoff value for enzyme immunoassay, 19 B. abortus-negative cattle blood sera were used. The average $\mathrm{OD}_{492}$ values of brucellosis negative sera were $0.119 \pm 0.005,0.078$ $\pm 0.003,0.059 \pm 003$ and $0.060 \pm 004$ at $1: 200$-fold dilution for i-ELISA/CSP, i-ELISA/rOmp25, i-ELISA/ rOmp31 and i-ELISA/rOmpBm-Ba, and the cutoff values were determined at $0.238,0.156,0.118$ and 0.120 , which were double the average $\mathrm{OD}_{492}$ of negative sera, respectively (Tab. 1).
Fig. 3. Electrophoregram of combined recombinant protein purified by metal-affinity chromatography

Explanations: 1 - elution of the rOmpBm-Ba with $500 \mathrm{mM} \mathrm{Im-}$ idazole; $\mathrm{M}$ - protein molecular weight marker

From Tab. 1 it follows that the antibodies of a certain part of animals seropositive by the results of conventional tests did not bind to the used rOmps, as well as CSP of B. abortus. Moreover, the antigenicity of the rOmps was different. The highest antigenic activity was shown by $\mathrm{rOmpBm}-\mathrm{Ba}$ which revealed anti-Brucella antibodies in the sera of $87(79.8 \%)$ of animals. rOmp25 and rOmp31 were recognized by the serum antibody of $79(72.5 \%)$ and $53(49.1 \%)$ animals, respectively. It should be noted that all positive results of $\mathrm{i}$-ELISA/rOmp25 and/or i-ELISA/rOmp31 were confirmed by immunoassay based on combined recombinant protein, and titers of antibodies were higher when rOmpBm-Ba was used as an antigen. For example, an antibody against a combined recombinant antigen was detected in the sera of $82(94.2 \%)$ cows in titres from $1: 200$ to $1: 800$, while such a level of antibody to rOmp25 and rOmp31 was established only in $51(64.5 \%)$ and $5(9.4 \%)$ animals, respectively. As can be seen from the Table, the results of the classical tests largely coincided with the readings of i-ELISA/ CSP of B. abortus. This option of immunoassay gave positive results for the presence of antibodies in serum

Tab. 1. Results of testing cattle sera $(n=109)$ by i-ELISA using Brucella rOmps

\begin{tabular}{|c|c|c|c|c|c|c|c|c|c|c|c|c|c|c|}
\hline \multirow{3}{*}{ Antigens } & \multirow{2}{*}{\multicolumn{2}{|c|}{$\begin{array}{l}\text { Serone-gative } \\
\text { cows by i-ELISA }\end{array}$}} & \multicolumn{12}{|c|}{ Antibody titers and the number of seropositive cows by i-ELISA } \\
\hline & & & \multicolumn{2}{|c|}{$1: 100$} & \multicolumn{2}{|c|}{$1: 200$} & \multicolumn{2}{|c|}{$1: 400$} & \multicolumn{2}{|c|}{$1: 800$} & \multicolumn{2}{|c|}{$1: 1600$} & \multicolumn{2}{|c|}{$1: 3200$} \\
\hline & $\mathrm{n}$ & $\%$ & $\mathrm{n}$ & $\%$ & n & $\%$ & $n$ & $\%$ & $\mathrm{n}$ & $\%$ & $\mathbf{n}$ & $\%$ & $\mathbf{n}$ & $\%$ \\
\hline $\mathrm{rOmpBm-Ba}$ & 22 & 20.2 & 5 & 4.6 & 22 & 20.2 & 31 & 28.4 & 29 & 26.6 & 0 & 0 & 0 & 0 \\
\hline r0mp25 & 30 & 27.5 & 28 & 25.7 & 33 & 30.3 & 17 & 15.6 & 1 & 0.92 & 0 & 0 & 0 & 0 \\
\hline r0mp31 & 56 & 51.2 & 48 & 44.0 & 5 & 4.6 & 0 & 0 & 0 & 0 & 0 & 0 & 0 & 0 \\
\hline CSP of $B$. abortus & 18 & 16.5 & 11 & 10.1 & 19 & 17.4 & 19 & 17.4 & 19 & 17.4 & 12 & 11 & 7 & 6.4 \\
\hline
\end{tabular}


samples of $91(86.6 \%)$ cattle. Furthermore, $80(76.1 \%)$ animals had the antibody titres in the range from $1: 200$ to $1: 3200$ with an average antibody titre of $1: 350$ $(+10.2 \% ;-9.3 \%)$. Mean i-ELISA antibody titre using rOmpBm-Ba, rOmp25 and rOmp31 were equal to $1: 260(+4.2 \% ;-4.0 \%), 1: 130(+4.2 \% ;-4.0 \%)$ and $1: 100(+1.4 \% ;-1.4 \%)$, respectively. A strong correlation was found between the results of i-ELISA/ rOmpBm-Ba - i-ELISA/rOmp25 (0.94) and i-ELISA/ rOmpBm-Ba - i-ELISA/rOmp31 (0.85). The average correlation was observed between readings of i-ELISA/ $\mathrm{CSP}$ and the immunoassay using rOmpBm-Ba (0.63), rOmp25 (0.59) and rOmp31 (0.41).

The diagnostic value of i-ELISA/rOmpBm-Ba was tested in comparison with the bacteriological analysis of pathological material (spleen, liver and lymph nodes) taken from 24 cows that reacted positively to brucellosis according to the results of the conventional tests that were used. The presence of anti-Brucella serum antibody $(1: 200-1: 400)$ was confirmed by i-ELISA/rOmpBm-Ba in only 15 animals (62.5\%). B. abortus was isolated from pathological material of 6 heads, with positive results by both AT and/or CFT and immunoassay. On the whole, from animals with positive results of conventional tests and i-ELISA/ rOmpBm-Ba the pathogen culture was isolated in $25 \%$ and $40 \%$ cases, respectively.

Thus, the obtained results indicate a possibility of improving the diagnostics of bovine brucellosis based on the use of a multiprotein recombinant antigen. This requires the availability of several producer strains that synthesize the diagnostically important rOmps of Brucella spp. In our view, however, a more rational approach is to create a single strain that produces two or more immunodominant regions of the pathogen.

In this study, a combined recombinant protein, designated as rOmpBm-Ba, consisting of the immunodominant regions of Brucella rOmp25 and rOmp31, has been successfully produced in E. coli and used to evaluate its antigenicity with the hope of increasing i-ELISA specificity for serodiagnosis of bovine brucellosis. The genes encoding rOmpBm-Ba were cloned and expressed in E. coli using the pET32 plasmids. The SDS-PAGE results showed the presence of a protein band of purified rOmpBm-Ba with mol.wt. $37.0 \mathrm{kDa}$. The expression of the $\mathrm{rOmpBm}-\mathrm{Ba}$ fusion protein in E. coli was also confirmed by western blot analysis using His Tag MAb.

The antigenicity of rOmpBm-Ba as compared with rOmp25and rOmp31 has been tested on the sera of 109 cattle with positive results to brucellosis according to AT and/or CFT. The combined recombinant protein had a higher antigenicity than the single ones, because it confirmed the presence of Brucella-antibody in all serum samples with positive results of i-ELISA/ rOmp25 and/or i-ELISA/rOmp31. Moreover, 7.3\% and $31.2 \%$ seropositive animals, respectively, were additionally revealed. This phenomenon, apparently, can be explained by the better availability of diagnostically important epitopes of rOmp25 and rOmp31 in the composition of the combined protein, rather than in original ones.

i-ELISA using CSP of B. abortus as an antigen showed the presence of specific antibodies in sera of $91(83.5 \%)$ seropositive animals by conventional test. In our opinion, the smaller number of seropositive cows detected by i-ELISA based on protein antigens as compared to classical tests indicates the possibility of obtaining false-positive results by AT and/or CFT that detect the antibody against the S-LPS of the Brucella cell membrane $(3,14,37)$. The higher antigenicity of B. abortus CSP as compared to recombinant proteins can be explained by the presence of nonspecific impurities in the in the composition of the antigen, because this preparation obtained by Tabatabai and Deyoe (35) is also not devoid of polysaccharides of the cell wall. Therefore, they may react with the antibody to S-LPS of the smooth vaccine strains and/or the other Gramnegative bacteria.

A comparative study of the diagnostic value of i-ELISA/rOmpBm-Ba and AT and/or CFT on the blood sera of cows subjected to a bacteriological examination at slaughter showed a higher reliability of the enzyme immunoassay using the combined Brucella recombinant protein: of the serum samples from the slaughtered animals which were seropositive by conventional tests only $62.5 \%(15 / 24)$ have been positive by i-ELISA/ rOmpBm-Ba, and its results were confirmed in $6(40 \%)$ of 15 cases. It is well known that although the recovery of the causative agent from the host is still the gold standard for brucellosis diagnosis, it has low sensitivity and can give somewhat ambiguous results (19). Therefore, the specificity of a test cannot usually be determined by culture isolation because some animals that are negative by the results of bacteriological assay are in fact infected $(7,28)$. Research is underway in our laboratory to conduct a more objective evaluation of the diagnostic accuracy of the combined recombinant protein of Brucella by challenging laboratory animals.

\section{References}

1.Ahmed I. M., Khairani-Bejo S., Hassan L., Bahaman A. R., Omar A. R.: Serological diagnostic potential of recombinant outer membrane proteins (rOMPs) from Brucella melitensis in mouse model using indirect enzymelinked immunosorbent assay. BMC Vet. Res. 2015, 11, 275 doi: 10.1186/ s12917-015-0587-2.

2. Akpinar 0. : Historical perspective of brucellosis: a microbiological and epidemiological overview. Infez. Med. 2016, 24, 77-86.

3. Baldi P. C., Giambartolomei G. H., Goldbaum F. A., Abdon L. F., Velikovsky C. A., Kittelberger R., Fossati C. A.: Humoral immune response against lipopolysaccharide and cytoplasmic proteins of Brucella abortus in cattle vaccinated with B. abortus S19 or experimentally infected with Yersinia enterocolitica serotype O:9. Clinical and Diagnostic Laboratory Immunology 1996, 3, 472-476.

4. Bradford M.: A rapid and sensitive method for the quantitation of microgram quantitates of protein utilizing the principle of protein - due binding. Anal. Biochem. 1976, 72, 248-225. 
5. Bulashev A. K. et al.: ELISA test based on the recombinant outer membrane protein of Brucella spp.: a report on the research work/KazATU S.Seifullin. 2015, 54. State registration \#: 0115RK02413. Inventory number 0215RK02093 (in Russian).

6. Bulashev A. K., Suranshiev Zh. A., Zhumalin A. Kh., Tursunov K.: Evaluation of Brucella antigens in serological diagnosis of brucellosis. Proc. of The IIER International Conference, Doha, Qatar $29^{\text {th }}$ June 2016, p. 1-3.

7. Cannon R. M., Roe R. T.: Livestock disease surveys: a field manual for veterinarians. Australian Bureau of Animal Health, Canberra 1982, p. 35.

8. Cassataro J., Pasquevich K., Bruno L., Wallach J. C., Carlos A. F., Pablo C. B.: Antibody Reactivity to Omp31 from Brucella melitensis in Human and Animal Infections by Smooth and Rough Brucellae. Clinical and Diagnostic Laboratory Immunology 2004, 111-114.

9. Chaudhuri P., Prasad R., Kumar V., Basavarajappa A. G.: Recombinan OMP28 antigen-based indirect ELISA for serodiagnosis of bovine brucellosis. Mol. Cell. Probes. 2010, 24, 142-145

10. Cloeckaert A., Verger J. M., Grayon M., Zygmunt M. S., Grepinet O. Nucleotide sequence and expression of the gene encoding the major 25-kilodalton outer membrane protein of Brucella ovis: Evidence for antigenic shift, compared with other Brucella species, due to a deletion in the gene. Infect. Immun. 1996, 64, 2047-2055.

11. Cloeckaert A., Vizcaíno N., Paquet J.-Y., Bowden R. A., Elzer P. H.: Major outer membrane proteins of Brucella spp.: past, present and future. Veterinary Microbiology 2002, 90, 229-247.

12. Connolly J. P., Comerci D., Alefantis T. G., Walz A., Quan M., Chafin R. Grewal P., Mujer C. V., Ugalde R. A., Delvecchio V. G.: Proteomic analysis of Brucella abortus cell envelope and identification of immunogenic candidate proteins for vaccine development. Proteomics 2006, 6, 3767-3780.

13. Contreras-Rodriguez A., Seleem M. N., Schurig G. G., Sriranganathan N., Boyle S. M., Lopez-Merino A.: Cloning, expression and characterization of immunogenic aminopeptidase $\mathrm{N}$ from Brucella melitensis. FEMS Immunology and Medical Microbiology 2006, 48, 252-256.

14. Corbel M. J.: Recent advances in the study of Brucella antigens and serological cross-reactions. Vet. Bull. 1985, 55, 927-942.

15. Corbel M. J., Elberg S. S., Cosivi O.: Brucellosis in humans and animals. Geneva: World Health Organization 2006, p. 13-21.

16. Debbarh H. S. A., Cloeckaert A., Bezard G., Dubray G., Zygmunt M. S.: Enzyme-linked immunosorbent assay with partially purified cytosoluble 28-kilodalton protein for serological differentiation between Brucella melitensisinfected and B. melitensis Rev.1-vaccinated sheep. Clin. Diagn. Lab. Immunol. 1996, 3, 305-308.

17. Erdenebaatar J., Bayarsaikhan B., Watarai M., Makino S., Shirahata T: Enzyme-linked immunosorbent assay to differentiate the antibody responses of animals infected with Brucella species from those of animals infected with Yersinia enterocolitica O:9. Clinical and Diagnostic Laboratory Immunology 2003, 10, 710-714.

18. Gupta V. K., Verma D. K., Singh S. V., Vihan V. S.: Serological diagnostic potential of recombinant outer membrane protein (Omp31) from Brucella melitensis in goat and sheep brucellosis. Small Rumin Res. 2007, 70, 260-266.

19. Kaltungo B. Y.: A review on diagnostic techniques for brucellosis. African Journal of Biotechnology 2014, 13, 1-10.

20. Kaur G., Verna R., Kumar B. V. S., Deka D., Agrawal R. K.: Cloning, Expression and Characterisation of Recombinant Outer Membrane Protein 16 from Brucella spp. Proc. Natl. Acad. Sci. India, Sect. B Biol. Sci. 2015, 85, 853-858.

21. Kisykov T.: Epidemiological situation with bovine brucellosis in Kazakhstan Veterinary 2009, 3, 44-46. (In Kazakh).

22. Ko K. Y.: Immunogenic proteins of Brucella abortus to minimize cross reaction in brucellosis diagnosis. Veterinary Microbiology 2012, 156, 374-380.

23. Laemmli $U$. K.: Cleavage of structural proteins during the assembly of the head of bacteriophage T4. Nature 1970, 227, 680-685.

24. Letesson J. J., Tibor A., Van Eynde G., Wansard V., Weynants V., Denoel P.: Humoral immune responses of Brucella-infected cattle, sheep, and goats to eight purified recombinant Brucella proteins in an indirect enzyme-linked immunosorbent assay. Clin. Diagn. Lab. Immunol. 1997, 4, 556-564.

25. Lim J. J., Kim D. H., Lee J. J., Kim D. G., Min W., Lee H. J., Rhee M. H., Chang H. H., Kim S.: Evaluation of Recombinant 28 kDa Outer Membrane Protein of Brucella abortus for the Clinical Diagnosis of Bovine Brucellosis in Korea. Journal of Veterinary Medical Science 2012, 74, 687-691.

26. Lindler L. E., Hadfield T. L., Tall B. D. et al.: Cloning of a Brucella melitensis group 3 antigen gene encoding Omp28, a protein recognized by the humora immune response during human brucellosis. Infect. Immun. 1996, 64, 2490$-2499$

27. Manat Y., Shustov A. V., Evtehova E., Eskendirova S. Z.: Expression, purification and immunochemical characterization of recombinant OMP28 protein of Brucella species. Open Veterinary Journal 2016, 6, 71-77.

28. Martin S. W.: The evaluation of tests. Can. J. comp. Med. 1977, 41, 19-25.
29. Moreno E., Moriyon I.: The Genus Brucella. Procariotes 2006, 5, 315-456.

30. Nicoletti P.: Brucellosis: past, present and future. Contributions, Sec. Biol. Med. Sci. MASA, XXXI, 2010, 21-32.

31. Sanger F., Nicklen S., Coulson A.: DNA sequencing with chain-terminating inhibitors. Proc. National Academy Sciences USA 1977, 74, 5463-5467.

32. Sayduldin T. S.: Statistical analysis of the results of serological tests. Veterinariya 1981, 7, 62-66 (in Russian).

33. Shevtsova E., Shevtsov A., Mukanov K. et al.: Epidemiology of Brucellosis and Genetic Diversity of Brucella abortus in Kazakhstan. PLoS One 2016, 11 doi: 10.1371/journal.pone.0167496.

34. Simborio H. L. T., Lee J. J., Reyes A. W. B., Hop H. T., Arayan L. T., Min W., Lee H. J., Yoo H. S., Kim S.: Evaluation of the combined use of the recombinant Brucella abortus Omp10, Omp19 and Omp28 proteins for the clinical diagnosis of bovine brucellosis. Microbial Pathogenesis 2015, 83-84, 41-46.

35. Tabatabai L. B., Deyoe D. L.: Biochemical and biological properties of soluble protein preparations from Brucella abortus. Developments in biological standardization 1984, 56, 199-211.

36. Towbin H., Staehelin T., Gordon J.: Electrophoretic transfer of proteins from polyacrylamide gels to nitrocellulose sheets: procedure and some applications. Proc. Natl. Acad. Sci. USA 1979, 76, 4350-4354.

37. Velasco J., Romero C., López-Goñi I., Leiva J., Díaz R., Moriyón I.: Evaluation of the relatedness of Brucella spp. and Ochrobactrum anthropi and description of Ochrobactrum intermedium sp. nov., a new species with a closer relationship to Brucella spp. International journal of systematic bacteriology 1998 , 48, 759-768

38. Vizcaino N., Cloeckaert A., Zygmunt M. S., Dubray G.: Cloning, nucleotide sequence, and expression of the Brucella melitensis omp31 gene coding for an immunogenic major outer membrane protein. Infection and Immunity 1996, 64, 3744-3751.

39. Vizcaino N., Kittelberger R., Cloeckaert A., Marin C. M., Fernandez-lago L. Minor Nucleotide Substitutions in the Omp31 Gene of Brucella ovis result in Antigenic Differences in the Major Outer Membrane Protein That It Encodes Compared to Those of the Other Brucella Species. Infection and immunity 2001, 7020-7028.

40. Vizcaino N., Verger J. M., Grayon M., Zygmunt M. S., Cloeckaert A.: DNA polymorphism at the omp-31 locus of Brucella spp.: evidence for a large deletion in Brucella abortus, and other species-specific markers. Microbiology $1997,143,2913-2921$

Corresponding author: Prof. Aitbay Bulashev, Department of Microbiology and Biotechnology, Faculty of Veterinary Medicine and Livestock Technology, S. Seifullin Kazakh Agro-Technical University, 010011, Astana, Kazakhstan; e-mail: aytbay57@mail.ru 